\title{
PROPOSAL FOR REASONABLE MEDIASTINAL LYMPHADENECTOMY IN BRONCHOGENIC CARCINOMAS: ROLE OF SUBCARINAL NODES IN SELECTIVE DISSECTION
}

Morihito Okada, MD

Noriaki Tsubota, MD

Masahiro Yoshimura, MD

Yoshifumi Miyamoto, MD
Objective: The aims of this study were to reveal the characteristics of skipping N2 lung cancer and to develop a more reasonable approach for dissecting mediastinal lymph nodes. Methods: Of consecutive 956 patients who were operated on for primary lung cancer from 1986 through 1996, $760(79.5 \%)$ had a diagnosis of non-small cell carcinoma and were subjected to complete resection of the tumor together with hilar and mediastinal lymphadenectomy. Results: Of 141 patients with N2 disease, $53(37.6 \%)$ had skipping metastases. Among 78 patients with N2 cancer of the upper lobe, $37(47.4 \%)$ had skipping metastases affecting upper or aortic mediastinal nodes whereas none of them had skipping metastases affecting lower mediastinal nodes. Among 47 patients with $\mathrm{N} 2$ cancer of the lower lobe, 13 (27.7\%) had skipping metastases affecting mediastinal nodes. Of these 13 patients, 11 (84.6\%) had skipping metastases affecting the subcarinal node. The remaining 2 patients had a huge primary tumor. Conclusions: Dissection of the upper part of the mediastinum including the aortic regions should be performed regardless of the operative appearance when cancer is located in the upper lobe, but it is not required for lower lobe tumors with negative hilar and subcarinal nodes. Dissection of the subcarinal node in patients with an upper lobe tumor is not routinely needed when the nodes in both the hilum and upper mediastinum are intact. We consider that the subcarinal node is of significance and skipping metastases should be defined as metastases that skip the subcarinal node in addition to $\mathrm{N} 1$ nodes. $(\mathrm{J}$ Thorac Cardiovasc Surg 1998;116:949-53)
$\mathrm{M}$ etastasis to mediastinal lymph nodes, found in approximately $20 \%$ to $40 \%$ of patients with non-small cell lung cancer, ${ }^{1,2}$ is one of the most important adverse factors for prognosis. ${ }^{3}$ Many physicians believe surgery is not indicated when N2 disease is found before thoracotomy, but some of these lesions demonstrate a favorable prognosis after complete surgical resection. ${ }^{4,5}$ Although hilar lymph nodes are anatomically positioned upstream from mediastinal lymph nodes, metastases to mediastinal nodes without metastases to hilar nodes are also seen and are called

From the Department of Thoracic Surgery, Hyogo Medical Center for Adults, Akashi City, Hyogo, Japan.

Received for publication Jan 26, 1998; revisions requested March 16, 1998; revisions received July 17, 1998; accepted for publication Aug 11, 1998.

Address for reprints: Noriaki Tsubota, MD, Department of Thoracic Surgery, Hyogo Medical Center for Adults, Kitaohji-cho 13-70, Akashi City 673, Hyogo, Japan.

Copyright $@ 1998$ by Mosby, Inc.

$0022-5223 / 98 \$ 5.00+0 \quad \mathbf{1 2} / \mathbf{1} / \mathbf{9 3 7 8 1}$ skipping metastases. ${ }^{6,7}$ The clinical significance of skipping metastases has to be clarified, and even the definition of skipping metastasis itself has not yet been generally agreed on. Meanwhile, it is hard to predict from macroscopic appearances whether a lymph node is involved or not. Large firm nodes are often free of disease, whereas small innocent-looking ones are diseased. Until now, we have believed that complete dissection of mediastinal nodes is necessary for a curative operation for lung cancer.

We reviewed the clinical records of patients with completely resected non-small cell lung cancer to assess the features and mode of mediastinal spread of the tumor cells to lymph nodes. The purposes of this study were to show the characteristics of skipping N2 lung cancer, to understand the significance of the carinal node in dissecting mediastinal lymph nodes, and to design a more effective and reasonable approach to lymphadenectomy. This is a surgical series of patients with lung cancer, all of whom had been subjected to complete resections with complete nodal resection. 
Table I. Profile of non-small cell carcinoma with complete resection and N2 dissection

\begin{tabular}{|c|c|c|c|c|c|c|}
\hline \multirow[b]{2}{*}{$N$ factor } & \multicolumn{6}{|c|}{ Location of tumor } \\
\hline & $R U L$ & $R M L$ & $R L L$ & $L U L$ & $L L L$ & Total \\
\hline pNO & 135 & 38 & 92 & 126 & 89 & 480 \\
\hline pN1 & 38 & 29 & 18 & 29 & 25 & 139 \\
\hline $\mathrm{pN} 2$ & 48 & 16 & 22 & 30 & 25 & 141 \\
\hline Total & 221 & 93 & 132 & 185 & 139 & 760 \\
\hline
\end{tabular}

$R U L$, Right upper lobe; $R M L$, right middle lobe; $R L L$, right lower lobe; $L U L$, left upper lobe; $L L L$, left lower lobe.

Table II. Profile of patients with N2 lung cancer of the so-called skipping and non-skipping groups

\begin{tabular}{lccc}
\hline Characteristic & $\begin{array}{c}\text { Skipping }(+) \\
(n=53)\end{array}$ & $\begin{array}{c}\text { Skipping }(-) \\
(n=88)\end{array}$ & $\begin{array}{c}\chi^{2} \\
\text { P value }\end{array}$ \\
\hline Age (y) & & & \\
Mean & $62 \pm 9.1$ & $62 \pm 9.7$ & \\
Range & $41-77$ & $33-78$ & .05 \\
Sex (male/female) & $35 / 18$ & $71 / 17$ & \\
Histology & & & .05 \\
Adenocarcinoma & 42 & 56 & .12 \\
Squamous cell & 11 & 29 & \\
$\quad$ carcinoma & & & \\
Others & 0 & 3 & .32 \\
T factor & & & .18 \\
T1 & 14 & 17 & .04 \\
T2 & 29 & 38 & .001 \\
T3 & 8 & 16 & .10 \\
T4 & 2 & 17 & .002 \\
Lobe of tumor & & & .59 \\
Right upper & 27 & 21 & .19 \\
Right middle & 3 & 13 & \\
Right lower & 2 & 20 & \\
Left upper & 10 & 20 & \\
Left lower & 11 & 14 & \\
Microscopic only & $17 / 36$ & & \\
positive/grossly positive & & & \\
\hline
\end{tabular}

This mode of selection of patients influences the prevalence of nodal metastases, which will be lower than in a series that includes all patients surgically treated for lung cancer, as in our preliminary report. ${ }^{8}$ Now we present the final results of our advanced study.

\section{Patients and methods}

Of 956 consecutive patients who were operated on for primary lung cancer by the same surgical team from January 1986 through December 1996, 760 (79.5\%) had non-small cell carcinoma and were subjected to complete resection of the tumor in combination with hilar and mediastinal lymphadenectomy. The patients' ages ranged from 30 to 88 years (mean $63 \pm 9.6$ years). The group included 568 men and 192 women. Whenever the parenchymal lesion was resectable, we tried to remove all lymph nodes to render the patient tumor free. Patients who had residual tumor at the resection margin or evidence of malignant effusion were excluded. Tumors with minute satellite nodules that were found incidentally within the same lobe of the resected specimen were not excluded from this study, because we were not certain whether these lesions should be considered local tumor spread. Tumors with satellite lesions in another lobe were excluded. Resected specimens were examined histopathologically and histologic typing was done according to the World Health Organization classification. ${ }^{9}$ Patients whose tumors were subsequently classified as small cell carcinoma or lowgrade malignant tumor were also excluded. The stage of the disease was determined on the basis of the criteria of the New International Staging System for Lung Cancer, ${ }^{3}$ including preoperative examinations, surgical findings, and pathologic results of resected specimens.

At operation, the lymph nodes of the ipsilateral thoracic cavity were completely resected. We performed complete dissection of all the hilar and mediastinal nodes in every case. Every node dissected en bloc (not sampled) was determined by surgeons to be macroscopically positive or negative during the operation and then examined by pathologists to be diagnosed as microscopically positive or negative after the operation. The sites of N2 lymph nodes were grouped as follows: upper mediastinal (highest mediastinal nodes, paratracheal nodes, pretracheal nodes, anterior mediastinal nodes, posterior mediastinal nodes, and tracheobronchial angle nodes), aortic (Botallo's nodes, para-aortic nodes, and ascending aortic nodes), and lower mediastinal (subcarinal nodes, paraesophageal nodes, and pulmonary ligament nodes) lymph nodes. N1 nodes comprised hilar nodes (main bronchus nodes, interlobar nodes, and lobar nodes). ${ }^{10,11}$ The results of macroscopic evaluation were compared with those of the pathologic examination. Mediastinal metastases were considered as so-called "skipping" metastases if any of the N2 nodes but no N1 nodes were involved. According to intraoperative appearance, metastatic lymph nodes were classified into grossly positive or microscopic-only positive (so-called false negative). Lymph nodes were immediately subjected to pathologic examination of the frozen section.

Patients were classified into the group bearing skipping metastases and the group having non-skipping metastases. The two groups were compared regarding several variables, and the differences between them were evaluated by means of the $\chi^{2}$ test. 


\section{Results}

Lymph node involvement was recognized in 280 (36.8\%) of the 760 patients evaluated: of the 280 patients, 139 patients $(18.3 \%)$ had N1 node involvement and $141(18.6 \%)$ had N2 node involvement. The relationship between the origin of the tumor and the pathologic $\mathrm{N}$ factor is presented in Table I. Of the 141 patients with N2 involvement, 53 (37.6\%) had skipping metastases. Their clinical profiles are shown in Table II. Although no statistically significant difference was observed, the incidence of skipping metastases was higher among women, patients with adenocarcinoma, and patients with microscopic-only positive N2 nodes.

Among 48 patients with $\mathrm{N} 2$ cancer of the right upper lobe, $27(56.3 \%)$ had skipping metastases involving the upper mediastinal nodes but not the lower mediastinal nodes. Of the 27 patients with skipping metastases, 9 (33.3\%) were considered to have microscopic-only positive nodes. Among 30 patients with N2 cancer of the left upper lobe, 10 (33.3\%) had skipping metastases involving the upper mediastinal or aortic lymph nodes but not the lower mediastinal lymph nodes. Of the 41 patients with tumors in the right or left upper lobe and non-skipping N2 metastases, that is, those who also showed N1 involvement, 16 (39.0\%) revealed subcarinal node involvement. Among 47 patients with N2 cancer of a lower lobe, $13(27.7 \%)$ had skipping metastases to mediastinal lymph nodes. Of these 13 patients, 11 $(84.6 \%)$ had skipping metastases to the subcarinal lymph node. Of the remaining 2 patients, 1 who had microscopic-only positive skipping metastases to Botallo's nodes had bronchioloalveolar carcinoma, pulmonary metastasis in the same lobe, and a tumor $80 \mathrm{~mm}$ in diameter. The other patient, who had microscopiconly positive skipping metastases to the paraesophageal (below carina) nodes, had a tumor $70 \mathrm{~mm}$ in diameter.

We investigated whether intraoperative misjudgment of N1 lymph node involvement had greatly affected selective dissection of $\mathrm{N} 2$ lymph nodes, because metastatic involvement of $\mathrm{N} 1$ nodes might influence the decision on the mode of lymphadenectomy for N2 nodes. Among 88 patients with non-skipping N2 cancer, $8(9.7 \%)$ had microscopic-only positive N1 nodes, which we mistook for negative nodes during the operation. Of the 5 patients with N2 cancer of an upper lobe with microscopic-only positive N1 metastases, 4 had metastases to the upper or aortic mediastinal lymph nodes. The remaining patient, who had metastasis to the subcarinal node, had a tumor $47 \mathrm{~mm}$ in diameter and invasion of the pericardium. All 3 patients who had N2 cancer of a lower lobe with microscopic-only positive $\mathrm{N} 1$ disease had metastases to the subcarinal node.

\section{Discussion}

In the present study, so-called skipping metastases to the mediastinal lymph nodes were recognized in approximately $37 \%$ of the resected $\mathrm{N} 2$ cases. This rate is close to those reported previously: $27 \%$ by Martini and colleagues, ${ }^{1} 28.6 \%$ by Ishida and colleagues, ${ }^{6}$ and $31.5 \%$ by Naruke. ${ }^{12}$ Positive nodes can be detected because of their macroscopic appearance during the operation in many instances. However, it is not rare to macroscopically misjudge whether a lymph node is involved. Therefore, if one has any doubt, the only option is to completely resect the nodes. For that reason complete dissection of the regional lymph nodes including mediastinum is the standard procedure for patients with lung cancer, even if no metastasis is observed in the hilar lymph nodes at the time of thoracotomy. However, the surgeon sometimes questions the wisdom of performing such a dissection when all the nodes are found to be negative in the postoperative pathologic examination. Skipping metastases are of clinical significance because skipping spread occurs almost predominantly in cases of adenocarcinomas and the location of skipping nodes is strongly affected by the origin of the primary tumor. For example, in our series in patients with tumors of an upper lobe, skipping involvement occurred exclusively in the upper part of the mediastinum. Therefore such important nodes should not be overlooked at the time of dissection or even for staging.

We cannot explain the striking predominance of adenocarcinoma among patients in whom only mediastinal metastases were found. In this series, of the 53 patients with skipping metastases, 42 (79.2\%) had adenocarcinoma. It is widely known that patients with adenocarcinoma have a poor prognosis, regardless of which parameters describing the cancer are compared, ${ }^{13}$ and our findings may explain this, at least in part. In addition, skipping metastases must be kept in mind even in cases of squamous cell carcinoma, inasmuch as 11 patients $(20.8 \%)$ had this cell type.

One possible mechanism for the development of skipping metastases may be the existence of lymphatic channels going directly to the mediastinum. Riquet and colleagues ${ }^{14}$ reported that subpleural lymphatics had direct passages to the mediastinal lymph nodes in $22 \%$ of the segments in the right lung and in $25 \%$ of the segments in the left lung. These investigators also stated that those direct passages were observed more frequently in the upper lobes, ${ }^{14}$ which might be one of the reasons why skipping metastases from the upper lobes occurred more frequently in this series.

The location of the tumor influenced the extent of nodal spread and the mode of nodal involvement. To 
compare the lymphatic routes with respect to site of the primary tumor, we divided the mediastinum into upper (including aortic) and lower regions. Metastatic spread may occur beyond the regional mediastinum into the nonregional mediastinum without involving lymph nodes of the regional mediastinum. Concerning skipping metastases from upper lobe lesions, in this series all 37 patients exhibited metastases to the upper region of the mediastinum, but none to the lower region. On the other hand, only 1 of 13 patients (7.7\%) with skipping metastases from lower lobe lesions showed nodal spread to the upper mediastinum only. Watanabe and colleagues ${ }^{15}$ also reported that the frequency of skipping metastases was only $22 \%$ from lower lobe lesions to the upper part of the mediastinum and merely $8 \%$ from upper lobe tumors to the lower part of the mediastinum. These results have something in common with findings reported by Hata, Troidl, and Hasegawa. ${ }^{16}$ They demonstrated by lymphoscintigraphy that the normal lymph drainage was through the regional mediastinum. From the lower lobe, only a small quantity of dye reached the upper mediastinal lymph nodes.

The question as to what extent of dissection should be considered reasonable and acceptable has so far attracted very little attention. In an attempt to answer it, we investigated subcarinal node involvement by analyzing metastatic spread to nodes. Rouviere ${ }^{17}$ described the subcarinal nodes as a crossroad where lymphatic vessels from the various organs in the thorax meet directly or by means of lymphoid relays, and communications are present between subcarinal nodes and all lobes of the lungs. Nohl ${ }^{18}$ stated that in upper lobe cancers, subcarinal lymph node metastases usually occurred as a result of involvement of nodes around the main bronchus and noted that subcarinal involvement was infrequent. Our data support these points. Among patients with the so-called skipping N2 metastases with an upper lobe lesion, none had positive subcarinal nodes. In case of upper lobe tumors, lower mediastinal nodes, including subcarinal nodes, were not involved if the hilar and upper mediastinal nodes were free from carcinoma cells. Therefore, in these cases, if the hilar and upper mediastinal nodes, including aortic nodes, were tumor-free, lower mediastinal lymphadenectomy was dispensable. Only 1 of the patients with non-skipping N2 metastases, an upper lobe lesion, and microscopic-only positive $\mathrm{N} 1$ involvement on intraoperative study had positive subcarinal nodes. A patient might be expected to have positive subcarinal nodes before the dissection was begun, based on the findings of pericardial invasion. On the other hand, of patients with lower lobe tumors showing both subcarinal and hilar negative nodes, only 1 patient had positive nodes in the upper part of the mediastinum; this patient had bronchioloalveolar type and pulmonary metastases in the same lobe. All of the patients with non-skipping N2 metastases and a lower lobe tumor presenting macroscopicnegative (microscopic-only positive) N1 metastases intraoperatively had positive subcarinal nodes. For these reasons, in these cases, upper mediastinal lymphadenectomy was dispensable when the hilar and subcarinal nodes were diagnosed to be tumor-free. We recommend an adequate use of frozen sections from key nodes. As an exception, in patients with an advanced stage of the disease based on findings such as extent of invasion, complete hilar/mediastinal lymphadenectomy should be routinely done so long as the patients are not at a high risk and are thought to be able to tolerate this surgical procedure. We therefore consider that the subcarinal node is of significance in defining skipping metastases and should be excluded from the definition of skip metastases to clarify its characteristics.

\section{REFERENCES}

1. Martini N, Flehinger BJ, Zaman MB, Beattie EJ. Results of resection in non-oat cell carcinoma of the lung with mediastinal lymph node metastases. Ann Surg 1983;198:386-97.

2. Massen W. Accuracy of mediastinoscopy. In: DeLarue NL, Eschapasse $\mathrm{H}$, editors. International trends in general thoracic surgery. Philadelphia: WB Saunders; 1985:42-53.

3. Mountain CF. A new international staging system for lung cancer. Chest 1986;89:225S-33S.

4. Patterson GA, Piazza O, Pearson FG, Todd TR, Ginsberg RJ, Goldberg M, et al. Significance of metastatic disease in subaortic lymph nodes. Ann Thorac Surg 1987;43:155-9.

5. Daly BD, Mueller JD, Faling LJ, Diehl JT, Bankoff MS, Karp $\mathrm{DD}$, et al. N2 lung cancer: outcome in patients with false-negative computerized tomographic scans of the chest. J Thorac Cardiovasc Surg 1993;105:904-11.

6. Ishida T, Yano T, Maeda K, Kaneko S, Tateishi M, Sugimachi K. Strategy for lymphadenectomy in lung cancer three centimeters or less in diameter. Ann Thorac Surg 1990;50:708-13.

7. Yoshino I, Yokoyama H, Yano T, Ueda T, Takai E, Mizutani K, et al. Skip metastasis to the mediastinal lymph nodes in non-small cell lung cancer. Ann Thorac Surg 1996;62:1021-5.

8. Tsubota N, Yoshimura M. Skip metastasis and hidden N2 disease in lung cancer: How successful is mediastinal dissection? Surg Today 1996;26:169-172.

9. World Heath Organization histologic typing of lung tumors. 2nd ed. Am J Clin Pathol 1982;77:123-36.

10. Naruke T, Suematsu K, Ishikawa S. Lymph node mapping and curability at various levels of metastasis in resected lung cancer. J Thorac Cardiovasc Surg 1978;76:832-9.

11. Martini N, Flehinger BJ, Zaman MB, Beattie EJ. Prospective study of 445 lung carcinoma with mediastinal lymph node metastases. J Thorac Cardiovasc Surg 1980;80:390-9.

12. Naruke T. Significance of lymph node metastases in lung cancer. Semin Thorac Cardiovasc Surg 1993;5:210-8. 
13. Mountain CF, Carr DT, Anderson WAD. A system for the staging of lung cancer. AJR 1974;120:130-8.

14. Riquet M, Hidden G, Debesse B. Direct lymphatic drainage of lung segments to the mediastinal nodes. $\mathrm{J}$ Thorac Cardiovasc Surg 1989;97:623-32.

15. Watanabe Y, Shimizu J, Tsubota M, Iwa T. Mediastinal spread of metastatic lymph nodes in bronchogenic carcinoma: mediastinal nodal metastases in lung cancer. Chest 1990;97:105965 .
16. Hata E, Troidl H, Hasegawa T. In-vivo-Untersuchungen der Lymphdrainage des Bronchialsystems beim Menschen mit der Lympho-Szintigraphie-eine neue diagnostische Technik. In: Hamelmann H, Troidl H, editors. Behandlung des Bronchialkarzinoms. 1st ed. Stuttgart: Georg Thieme Verlag; 1981. p. 27-34.

17. Rouviere H. Anatomy of the human lymphatic system. Ann Arbor $\{\mathrm{MI}]$ : Edwards Brothers; 1938. p. 83-101.

18. Nohl HC. The spread of carcinoma of the bronchus. London: Lloyd-Luke Ltd; 1962. p. 17-44.

\section{ON THE MOVE?}

Send us your new address at least six weeks ahead

Don't miss a single issue of the journal! To ensure prompt service when you change your address, please photocopy and complete the form below.

Please send your change of address notification at least six weeks before your move to ensure continued service. We regret we cannot guarantee replacement of issues missed due to late notification.

\section{JOURNAL TITLE:}

Fill in the title of the journal here.

\section{OLD ADDRESS:}

Affix the address label from a recent issue of the journal here.

\section{NEW ADDRESS: \\ Clearly print your new address here.}

Name

Address

City/State/ZIP

\section{COPY AND MAIL THIS FORM TO:}

Periodical Subscription Services

Mosby, Inc.

11830 Westline Industrial Dr.

St. Louis, MO 63146-3318
OR FAX TO:

314-432-1158

N/ Mosby

\section{OR PHONE:}

$1-800-453-4351$

Outside the U.S., call

314-453-4351 